Research Article

\title{
A Comparative Study regarding Assertiveness, Self-esteem and Leadership Potentiality between Students of Selected Nursing and General College in West Bengal
}

\author{
Soma Chakraborty', Aparna Ray², Smriti Kana Mani ${ }^{3}$ \\ ${ }^{1}$ Sister Tutor, Nursing Training School, College of Medicine \& Sagore Dutta Hospital, Kolkata, West Bengal, India. \\ ${ }^{2}$ Senior Lecturer, ${ }^{3}$ Principal, College of Nursing, Medical College \& Hospital, Kolkata, West Bengal, India. \\ DOI: https://doi.org/10.24321/2455.9318.202019
}

I $\quad \begin{array}{lllll}\mathbf{N} & \mathbf{F} & \mathbf{O}\end{array}$

\author{
Corresponding Author: \\ Soma Chakraborty, Nursing Training School, \\ College of Medicine \& Sagore Dutta Hospital, \\ Kolkata, West Bengal, India. \\ E-mail Id: \\ goheenbabu@gmail.com \\ Orcid Id: \\ https://orcid.org/0000-0003-4177-8401 \\ How to cite this article: \\ Chakraborty S, Ray A, Mani SK. A Comparative \\ Study regarding Assertiveness, Self-esteem and \\ Leadership Potentiality between Students of \\ Selected Nursing and General College in West \\ Bengal. Int J Nurs Midwif Res 2020; 7(3): 4-11. \\ Date of Submission: 2020-08-22 \\ Date of Acceptance: 2021-02-11
}

\section{$\begin{array}{llllllll}\mathbf{A} & \mathbf{B} & \mathbf{S} & \mathbf{T} & \mathbf{R} & \mathbf{A} & \mathbf{C} & \mathbf{T}\end{array}$}

Introduction: Nursing is a philanthropic profession and has a rich historical background. Nursing is an integral component of the entire health care delivery system. The objective of nursing education is to foster high standards of nursing practice and advancement of the profession and the reciprocal objective of nursing is to establish, promote and implement nursing education.

Materials and Methods: A comparative survey study was conducted to assess and compare assertiveness, self-esteem and leadership potentiality between 64 (sixty-four) 3rd year B.Sc. nursing students of College of Nursing, Medical College \& Hospital, Kolkata; Government College of Nursing, S.S.K.M. Hospital, Kolkata and 60 (sixty) General college students of Brahmananda Keshab Chandra College, Bonhooghly, Kolkata, West Bengal. Non-probability purposive sampling technique was adopted. The tool consisted of socio-demographic profile, standardized tool for assessment of assertiveness and self-esteem and 30 item structured questionnaire for assessment of leadership potentiality.

Result: The study findings reveal that assertiveness (mean difference $=0.74$ ), self-esteem (mean difference $=3.47$ ) and leadership potentiality (mean difference=7.19) among general college students are higher than those of nursing college students. The results also indicate that assertiveness is positively correlated with self-esteem [ " $\mathrm{t}$ " $\mathrm{df}(58)=2.00$; $p<0.05$ ] and leadership potentiality [ $" t$ " $d f(58)=2.00 ; p<0.05$ ] among general college students.

Conclusion: Investigator concludes that it is necessary to think about the enhancement of those three vital aspects. It can be done by modifying nursing education curriculum so that nursing students can improve professional skills and carry forward their professional legacy.

Keywords: Assertiveness, Self-esteem, Leadership Potentiality, Nursing College Students, General College Students 


\section{Introduction}

Assertiveness is a style of communication, an important tool for expressing oneself confidently. It enables nurses to build effective team relationships, improve the quality of patient care. ${ }^{1}$ One of the studies recommends that incorporation of structured tutorial support is needed to endorse selfcontrol, self-reliance, assertiveness and empowerment.

Morris Rosenberg defines self-esteem in term of a stable sense of personal worth or worthiness. "Self-esteem breaks down into two components: (1) the ability to say that "I am important," "I matter" and (2) the ability to say, "I am competent," "I have something to offer to others and the world". ${ }^{2}$ Self-esteem is one of the most important factors affecting mental health as well as occupational behaviors of nurses.

Leadership is using "interpersonal skills to influence others towards goal achievement." According to some other researchers, leadership is not only a set of skills that are expected to be incorporated into nurses through nursing education, but also an attitude which introduces certain behavioural patterns. A variety of leadership behaviour are required in nursing practice to work efficiently by keeping pace with the change in environment. ${ }^{3}$ Nurses are frontline caregivers and play a vital role in optimum utilization of leadership behaviour.

According to study findings of Larijani TT et al., ${ }^{5}$ majority of $(71.1 \%)$ nursing students had deficit assertiveness in Tehran. In a comparative study by Duruk $\mathrm{N}$ et al. ${ }^{6}$ in Turkey, it revealed that senior nursing students had higher selfesteem than sophomore nursing students. Dharsini DDP, Jebaseelan US ${ }^{7}$ conducted a study on college students in Tamil Nadu, which exhibited maximum students were having moderate level of self-esteem. In a study by $A b d r b o A^{3}$ on B.Sc. Nursing students from different clinical discipline, researcher recommended provision of constant leadership training to cover up the existing scarcity of nurse leaders worldwide.

The nursing profession requires a high degree of personal and group interaction. Assertiveness, self-esteem and leadership potentiality are the precursors of such interactions.

Development of assertiveness and effective communication skills should begin from the training programme where students are taught to express their feelings, desires and stand for their own rights. Assertive behaviour shall help them in effective communication with client, building a trustworthy relationship, gaining confidence and ultimately accelerating the therapeutic patient care in future. ${ }^{1}$

Self-esteem plays an important role in building the unique identity of an individual student nurse. Studies indicate that perceived health status, satisfaction with academic life, peer cohesiveness, academic grades are positively correlated with high self-esteem. On the contrary, low self-esteem is correlated with depression and suicidal ideation. ${ }^{8}$ So, it is crucial to develop high self-esteem among today's faculty students, to ensure safe and competent practice. ${ }^{9}$

Nursing education is not only aimed at preparing personnel as good leaders but also has an additional responsibility in identifying potential leaders and fostering their development. ${ }^{10}$ Leadership potentiality is a future matter of concern regarding development of efficient leaders. So, critical analysis of assessment of leadership potentiality provides necessary data and focuses the scope and way of advancement in leadership quality among future nurse leaders.

As pupil nurses begin their nursing education in the young adult phase, they can be molded for future profession. Studies regarding assertiveness, self-esteem leadership potentiality and many other human concerns should be highlighted so that the human resource meant for the nursing profession may become more productive and enthusiastic towards their profession.

A student nurse is not just a nursing student but the future of nursing. So, nursing students are the nucleus of future professional nurses, hence, it is necessary to assess assertiveness, self-esteem, leadership potentiality among nursing students. ${ }^{4}$

There is a great shortage of extensive work regarding selfesteem and assertiveness of nursing students. Very few literatures are available regarding these two aspects of nursing students. It seems to be difficult to access literature exactly on leadership. Moreover, the investigator did not find any study on assertiveness, self-esteem and leadership potentiality, taken together, among nursing students.

For these reasons the investigator was eager to assess levels of assertiveness, self-esteem and leadership potentiality among nursing students, in comparison with general college student.

\section{Objectives}

- To assess assertiveness, self-esteem and leadership potentiality of students of selected nursing college and selected general college in West Bengal.

- To compare assertiveness, self-esteem and leadership potentiality of students between selected nursing college and selected general college in West Bengal.

- To find out the relationship between assertiveness, selfesteem and leadership potentialities among nursing college students and general college students.

\section{Materials and Methods}

Quantitative research approach and comparative survey 
design was selected. The study settings were two nursing colleges, College of Nursing, Medical College \& Hospital, Kolkata and Government College of Nursing, S.S.K.M. Hospital, Kolkata and one general college, Brahmananda Keshab Chandra College, Bonhooghly, Kolkata, West Bengal. Non-probability purposive sampling technique was adopted to select 64 (sixty-four) nursing college students and 60 (sixty) general college students. The inclusion criteria were abilities to read and write in English.

The tool comprised of four parts. Part 1 - Socio-demographic proforma consisting of 10 item that is, age of the student, residence, birth order, type of family, educational level of mother, educational level of father, occupation of father, occupation of mother, monthly family income, previous experience living in hostel. Part 2 - Rathus Assertiveness Schedule - a standardized tool was used to assess assertiveness level, developed by Rathus in 1973, consisting of 30-item 6-grade Likert scale which was easily answerable by an individual. The scale is described in the following six characteristics. Scoring pattern is following: Very Non-Assertive: -90 to -20, situationally non-assertive: -20 to 0, Somewhat Assertive: 0 to +20 , Assertive: +20 to +40 , Probably Aggressive: +40 to +90 . Reliability of Rathus Assertiveness Schedule - Internal consistency is 0.77 (split half method), stability of the tool is 0.78 (test-retest). Part 3 - Rosenberg Self-Esteem Scale - a standardized tool was used to assess self-esteem level, was developed by sociologist Dr. Morris Rosenberg. This tool represents a continuum of self-worth statement ranging from low self-esteem to high self-esteem. It is 10-item Likert scale with four points from strongly agree, agree, disagree to strongly disagree. Sum score of 10 items to be plotted in a continuous scale. Higher scores indicate higher self-esteem. Reliability of Rosenberg Self-Esteem Scale - stability of the tool is ranges from 0.82-0.88 (test-retest) and internal consistency of the tool is ranges from $0.77-0.88$ (split half method). Part 4 - Structured questionnaire for assessment of leadership potentiality was developed after validating experts from the field of Psychiatric Nursing and Clinical Psychology, modifying of first draft of questionnaire and pretested. It consisted of 30 questions, 5-graded Likert scale including domain on 'persuasiveness', 'effective communication skill', 'self-confidence', 'self-discipline', 'effective decision making', 'problem solving', 'accountability', 'self-awareness', 'goal oriented and adequate planning', 'willing to take risk and to be different', 'capable to handle criticism' and 'encourage others. Total score was150. Scoring pattern is following: Great leader- 135-150, Good leader- 120-134, Emerging leader-105-119, bursting to potential- 90-104, Need growth- Below 90. Reliability of the tool (internal consistency) is ranges from 0.88 (Cronbach's Alpha method). Institutional ethical clearance was obtained. Informed consent was taken from willing participants. Anonymity and confidentiality were ensured by coding.

Data were analyzed using descriptive and inferential statistics, using Microsoft-XL. Frequency and percentage were computed for describing the sample characteristics. Computation of mean, mean difference, standard deviation and unpaired ' $t$ ' test of assertiveness, self-esteem and leadership potentiality score between the both groups. Computation of Pearson ' $\mathrm{R}$ ' for determining correlation between assertiveness, self-esteem and leadership potentiality among both groups of students.

\section{Result}

\section{Findings Related to Demographic Characteristics}

This section highlights the demographic characteristics of the students.

Table 1, depicts that majority of students in general college $(97 \%)$ and nursing college $(78 \%)$ are in the less than 21 -years age group. Majority (95\%) of general college students are urban dwellers whereas majority (64\%) of nursing college students are from rural areas. Majority (73\%) of general college students and maximum nursing college students $(52 \%)$ are the first child of their parents. Educational qualification of fathers of maximum general college students $(36 \%)$ is up to the secondary level, and in the case of nursing colleges student's fathers of majority (52\%) studied up to the graduation level and above. Educational qualification of mothers of maximum general college students (38\%) and majority nursing college students $(51 \%)$ is up to the secondary level. Fathers of the majority of general college students (52\%) and nursing college students (55\%) are selfemployed by profession. Mothers of the majority general college students (90\%) and nursing college students (81\%) are homemakers. Monthly Family Income of majority of general college students (52\%) and maximum of nursing college students (33\%) is up to Rs. 10,000 (ten thousand). Majority of general college students (93\%) do not have previous experience of living in hostels. On the contrary, majority of nursing college students (56\%) have previous experience of living in hostels.

\section{Findings Related to Assertiveness among Students}

It highlights assertiveness score among nursing and general college students (Figure 1 and Table 2).

Figure 1, shows that majority of general college students (50\%) and nursing college students (59\%) are 'Somewhat Assertive', whereas, 22\% of general college students and 19\% of nursing college students are 'Situationally Non-Assertive'. $22 \%$ of general college students and $14 \%$ of nursing college students are 'Assertive'. $6 \%$ of general college students and $8 \%$ of nursing college students are 'Very Non-Assertive'. 
Chakraborty $S$ et al. Int. J. Nurs. Midwif. Res. 2020; 7(3)

Table I.Findings related to demographic characteristics

\begin{tabular}{|c|c|c|c|}
\hline \multicolumn{2}{|c|}{ Demographic characteristics } & General College student & Nursing College student \\
\hline \multirow{2}{*}{ Age in years } & $\leq 21$ & $97 \%$ & $78 \%$ \\
\hline & $>21$ & $3 \%$ & $22 \%$ \\
\hline \multirow{3}{*}{ Birth order } & First & $73 \%$ & $52 \%$ \\
\hline & Middle & $7 \%$ & $25 \%$ \\
\hline & Last & $20 \%$ & $23 \%$ \\
\hline \multirow{2}{*}{ Residential area } & Rural & $5 \%$ & $64 \%$ \\
\hline & Urban & $95 \%$ & $36 \%$ \\
\hline \multirow[t]{2}{*}{ Type of family } & Joint & $32 \%$ & $17 \%$ \\
\hline & Nuclear & $68 \%$ & $83 \%$ \\
\hline \multirow{4}{*}{$\begin{array}{l}\text { Educational status of } \\
\text { father }\end{array}$} & $\begin{array}{c}\text { Graduate \& } \\
\text { Above }\end{array}$ & $30 \%$ & $33 \%$ \\
\hline & High Secondary & $23 \%$ & $10 \%$ \\
\hline & Secondary & $27 \%$ & $36 \%$ \\
\hline & Primary & $20 \%$ & $2 \%$ \\
\hline \multirow{4}{*}{$\begin{array}{l}\text { Educational status of } \\
\text { mother }\end{array}$} & $\begin{array}{c}\text { Graduate \& } \\
\text { Above }\end{array}$ & $27 \%$ & $25 \%$ \\
\hline & High Secondary & $20 \%$ & $16 \%$ \\
\hline & Secondary & $38 \%$ & $51 \%$ \\
\hline & Primary & $15 \%$ & $8 \%$ \\
\hline \multirow{4}{*}{ Occupation of father } & Un-employed & $5 \%$ & $5 \%$ \\
\hline & Pensioner & $3 \%$ & $3 \%$ \\
\hline & Service & $40 \%$ & $37 \%$ \\
\hline & Self-employed & $52 \%$ & $55 \%$ \\
\hline \multirow{4}{*}{ Occupation of mother } & House-wife & $90 \%$ & $81 \%$ \\
\hline & Pensioner & $5 \%$ & $2 \%$ \\
\hline & Service & $3 \%$ & $14 \%$ \\
\hline & Self-employed & $2 \%$ & $3 \%$ \\
\hline \multirow{6}{*}{ Monthly family income } & $\leq 5,000$ & $18 \%$ & $12 \%$ \\
\hline & $\leq 10,000$ & $52 \%$ & $33 \%$ \\
\hline & $\leq 20,000$ & $13 \%$ & $23 \%$ \\
\hline & $\leq 30,000$ & $8 \%$ & $11 \%$ \\
\hline & $\leq 50,000$ & $7 \%$ & $16 \%$ \\
\hline & $>50,000$ & $2 \%$ & $5 \%$ \\
\hline \multirow{2}{*}{$\begin{array}{l}\text { Previous experience of } \\
\text { living in hostel }\end{array}$} & Yes & $7 \%$ & $56 \%$ \\
\hline & No & $93 \%$ & $44 \%$ \\
\hline
\end{tabular}

Table 2, indicates that the mean assertiveness score of general college students (7.37) is higher than that of nursing college students (6.63). The mean difference $(0.74)$ is not statistically significant as evident from independent ' $\mathrm{t}$ ' test [“t” df (122) = 0.26; $p=0.79$ ]. 


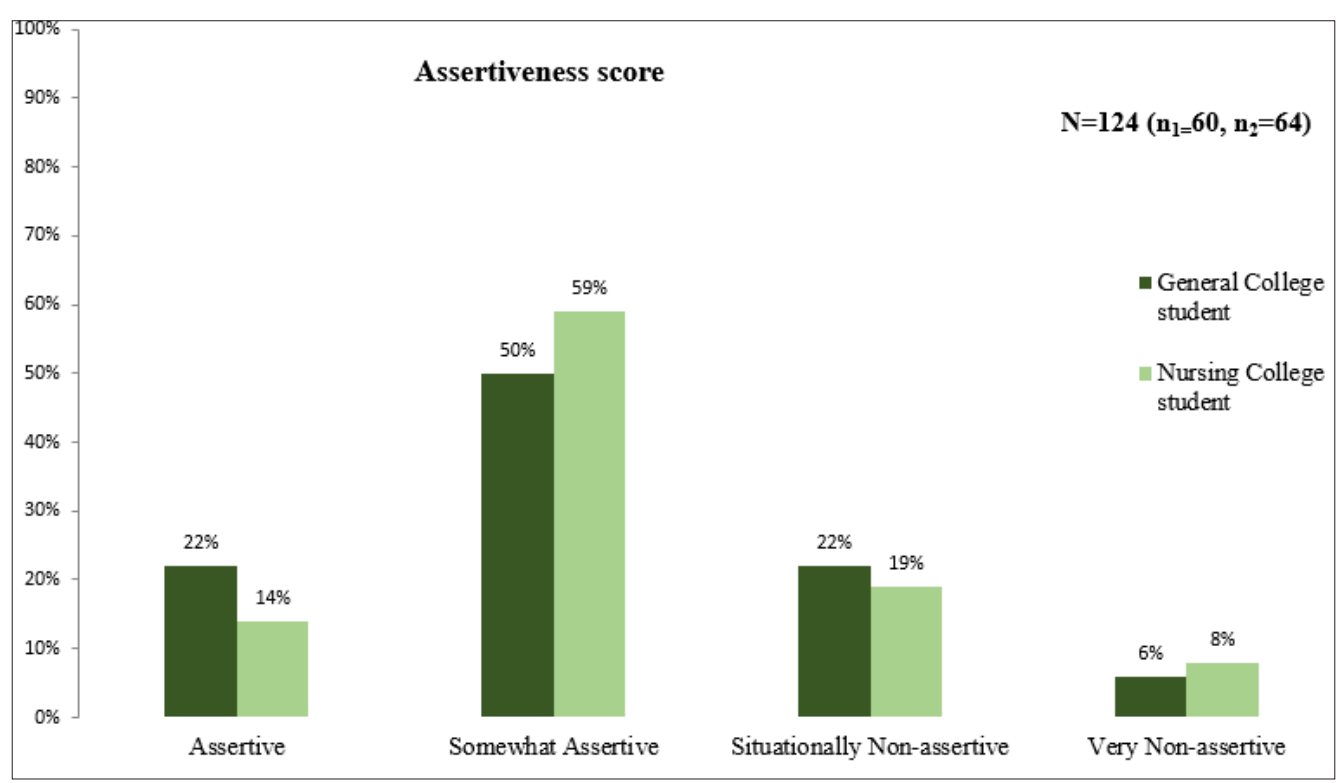

Figure I.Column diagram showing percentage distribution of general \& nursing college students according to their assertiveness scores

Table 2.Mean, mean difference, standard deviation and ' $t$ ' between assertiveness scores among general college and nursing college

\begin{tabular}{|c|c|c|c|c|c|}
\hline \multicolumn{4}{|c|}{$[\mathrm{N}=124(\mathrm{n} 1=60, \mathrm{n} 2=64)]$} \\
\hline Item & Total score & Mean score & Mean difference & SD & t-value \\
\hline General college student & 442 & 7.37 & \multirow{2}{*}{0.74} & 16.34 & \multirow{2}{*}{0.26} \\
\cline { 1 - 3 } \cline { 5 - 6 } & 424 & 6.63 & & 15.1 & \\
\hline
\end{tabular}

"t" df (122) $=1.98 ; \mathrm{p}<0.05 ;{ }^{*}$ significant.

\section{Findings Related to Self-esteem among Students}

It shows the findings related to self-esteem scores of nursing and general college students (Figure 2 and Table 3).

Figure 2 shows that majority of general college students
(95\%) and nursing college students (70\%) have 'High Selfesteem'. Rest $5 \%$ of general college students and $30 \%$ of nursing college students have 'Normal Self-esteem'. No student shows 'Low Self-esteem'.

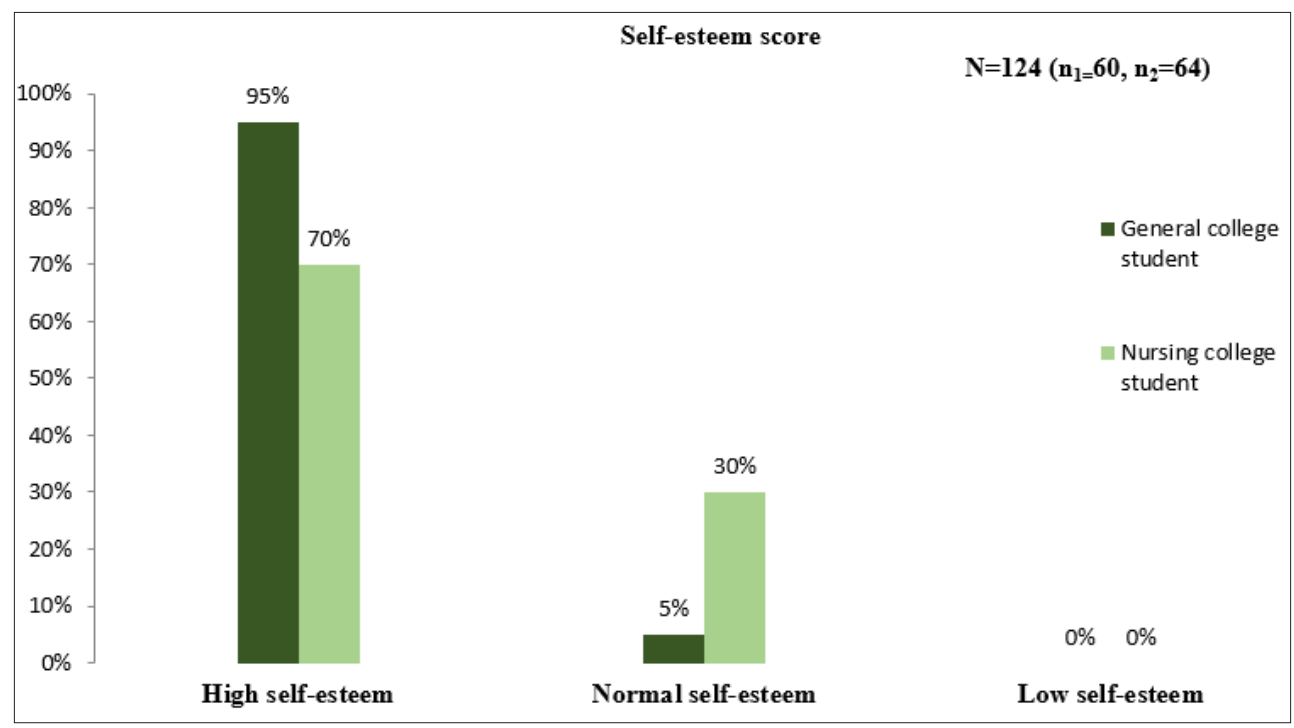

Figure 2.Column diagram depicting percentage distribution of general \& nursing college students according to their self-esteem scores 
Table 3.Mean, mean difference, standard deviation and ' $t$ ' between self-esteem scores among general college and nursing college students

$[\mathrm{N}=124(\mathrm{n} 1=60, \mathrm{n} 2=64)]$

\begin{tabular}{|c|c|c|c|c|c|}
\hline Item & Total score & Mean score & Mean difference & SD & ' $t$ ' value \\
\cline { 1 - 3 } General college student & 1210 & 20.17 & \multirow{2}{*}{3.47} & 3.25 & \multirow{2}{*}{6.31} \\
\cline { 1 - 2 } \cline { 5 - 7 } & 1069 & 16.7 & & 3.11 & \\
\hline
\end{tabular}

"t" df (122) =1.98; $p<0.05 ;$ *significant.

Table 3, indicates mean self-esteem score of general college students (20.17) is higher than that of nursing college students (16.7). The mean difference (3.47) is statistically significant as evident from independent ' $t$ ' test [ $t$ " df (122) = 6.31; $\mathrm{p}=0.000001]$.

\section{Findings Related to Leadership Potentiality among Students}

It shows the leadership potentiality among nursing and general college students (Figure 3 and Table 4).

Figure 3, shows that majority of general (47\%) and nursing $(63 \%)$ college students are 'Emerging Leader'. 38\% of general college students and $9 \%$ of nursing college students are 'Good Leader'. Only $2 \%$ of general college students are 'Great leader'. But there is no student from nursing colleges in this category. Whereas $12 \%$ general and $27 \%$ nursing college students are 'Bursting to Potential', $2 \%$ of students from each group 'Need Growth'.

Table 4, indicates that mean leadership potentiality score of general college students (115.78) is higher than that of nursing college students (108.59). The mean difference (7.19) is statistically significant as evident from independent ' $t$ ' test [" $t$ " df (122) = 4.3; $p=0.000035]$.

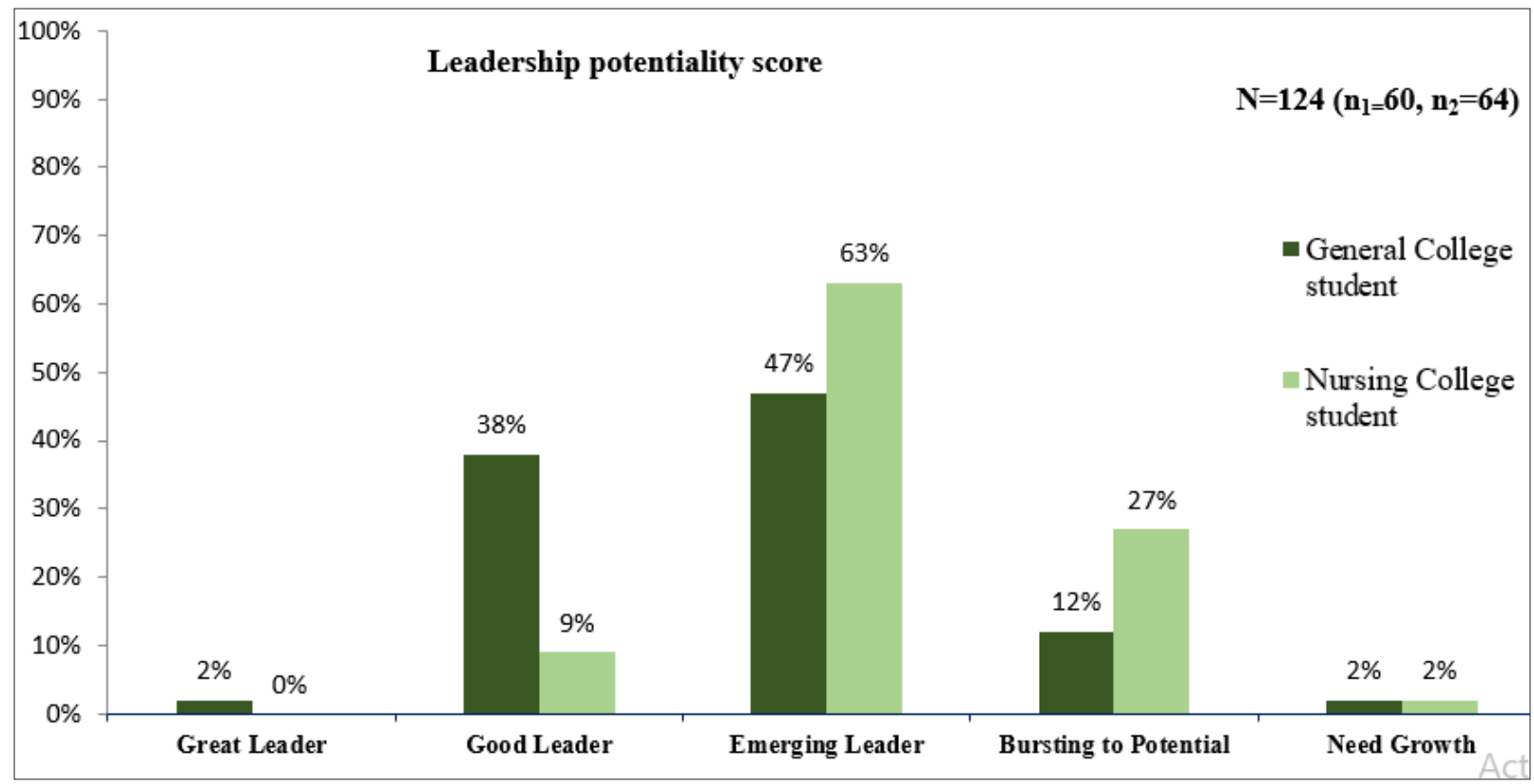

Figure 3.Column diagram depicting percentage distribution of general and nursing college students according to their leadership potentiality scores

Table 4.Mean, mean difference, standard deviation and ' $t$ ' between leadership potentiality scores among general college and nursing college students

\begin{tabular}{|c|c|c|c|c|c|}
\hline \multicolumn{6}{|c|}{$[\mathrm{N}=124(\mathrm{n} 1=60, \mathrm{n} 2=64)]$} \\
\hline Item & Total score & Mean score & Mean difference & SD & 't' value \\
\hline General college student & 6947 & 115.78 & \multirow{2}{*}{7.19} & 11.39 & \multirow{2}{*}{4.3} \\
\hline Nursing college student & 6950 & 108.59 & & 8.19 & \\
\hline
\end{tabular}

"t" df (122) =1.98; $p<0.05 ;$ *significant. 
Findings of Relationship between Assertiveness and Self-esteem, Self-esteem and Leadership Potentiality, Leadership Potentiality and Assertiveness among General College Students

It presents the relationship between assertiveness and self-esteem, self-esteem and leadership potentiality, leadership potentiality and assertiveness among general college students (Table 5).

Table 5 depicts that there is significant positive correlation between assertiveness and self-esteem $[r=0.3, t=2.4$ for $\mathrm{df}$ (58) at 0.05 level]. There is significant positive correlation between assertiveness and leadership potentiality $[r=0.4$, $t=3.33$ for $\mathrm{df}$ (58) at 0.05 level]. The data also shows that there is no significant correlation between self-esteem and leadership potentiality $[\mathrm{r}=0.2, \mathrm{t}=1.56$ for $\mathrm{df}(58)$ at 0.05 level].

Findings Related to Relationship between Assertiveness and Self-esteem, Self-esteem and Leadership Potentiality, Leadership Potentiality and Assertiveness among Nursing College Students

It highlights the relationship between assertiveness and self-esteem, self-esteem and leadership potentiality, leadership potentiality and assertiveness among nursing college students (Table 6).

Table 6 depicts that there is no significant correlation between assertiveness and self-esteem $[r=0.2, t=1.61$ for $\mathrm{df}$ (62) at 0.05 level]. There is no significant correlation between assertiveness and leadership potentiality $[\mathrm{r}=0.08, \mathrm{t}=0.01$ for $\mathrm{df}$ (62) at 0.05 level]. There is significant correlation between self-esteem and leadership potentiality $[r=0.3$, $\mathrm{t}=2.48$ for $\mathrm{df}(62)$ at 0.05 level].

\section{Discussion}

The overall study results reveal that of $59 \%$ nursing college students are 'Somewhat Assertive' and only $14 \%$ of nursing college students are 'Assertive'. They have shown lower mean score (statistically non-significant) in this context than general college students. This study findings are consistent with the studies conducted by Larijani TT et al. ${ }^{5}$ and Okuyama A et al. ${ }^{10}$ Larijani TT et al. ${ }^{5}$ conducted a descriptive cross-sectional study on 173 nursing students (68 male and 105 female) at Tehran University of Medical Sciences in 2007-2008 which reported most of the students (71.1\%) were deficient in assertiveness. In a literature review by Okuyama A et al. ${ }^{10}$ in 2014 regarding 'How we can enhance nurse's assertiveness' concluded that in spite of being trained from higher educational institutions, still there are nowadays difficulties regarding self-assessment among nurses. Moreover, it became essential for nurse managers to lead juniors towards assertiveness.

The study also identifies that majority of nursing college students (70\%) have 'High Self-esteem' and only $30 \%$ of nursing college students have 'Normal Self-esteem'. Again, they have shown a statistically significant lower mean score in this context than general college students. The study findings of Duruk, Kurban and Kurban ${ }^{6}$ in comparative study in 2017 in Turkey between two groups (158 nos.) of nursing students, supports the findings that majority students (A57\%, B-55.8\%) exhibited high self-esteem.

The study emphasized $63 \%$ nursing college students are 'Emerging Leaders', 27\% nursing college students are 'Bursting to Potential', 9\% are 'Good Leaders' and only 2\% are 'Great leaders. Regarding leadership potentiality also

Table 5.Relationship between assertiveness and self-esteem, self-esteem and leadership potentiality, leadership potentiality and assertiveness among general college students

$(n 1=60)$

\begin{tabular}{|c|c|c|c|c|c|c|}
\hline \multirow{2}{*}{ Variables } & \multicolumn{3}{|c|}{ Self-esteem } & \multicolumn{3}{c|}{ Leadership potentiality } \\
\cline { 2 - 7 } & $\begin{array}{c}\text { Pearson correlation } \\
\text { coefficient ( } \mathbf{r} \text { ) }\end{array}$ & ' $\mathrm{t}$ ' value & *S/NS & $\begin{array}{c}\text { Pearson correlation } \\
\text { coefficient }(\mathbf{r})\end{array}$ & ' $\mathrm{t}$ ' value & *S/ NS \\
\hline Assertiveness & 0.3 & 2.4 & $* S$ & 0.4 & 3.33 & $* S$ \\
\hline Self-esteem & - & - & - & 0.2 & 1.56 & NS \\
\hline
\end{tabular}

“t” df (58) = 2.00; $\mathrm{p}<0.05 ;$ *Significant $\left({ }^{*} \mathrm{~S}\right) /$ Not significant (NS).

Table 6.Relationship between assertiveness and self-esteem, self-esteem and leadership potentiality, leadership potentiality and assertiveness among nursing college students

(n2=64)

\begin{tabular}{|c|c|c|c|c|c|c|}
\hline \multirow{2}{*}{ Variables } & \multicolumn{3}{|c|}{ Self-esteem } & \multicolumn{3}{c|}{ Leadership potentiality } \\
\cline { 2 - 7 } & $\begin{array}{c}\text { Pearson correlation } \\
\text { coefficient ( } r \text { ) }\end{array}$ & ' $t$ ' value & *S/ NS & $\begin{array}{c}\text { Pearson correlation } \\
\text { coefficient ( } \mathbf{r})\end{array}$ & ' $t$ ' value & *S / NS \\
\hline Assertiveness & 0.2 & 1.61 & NS & 0.08 & 0.01 & NS \\
\hline Self-Esteem & - & - & - & 0.3 & 2.48 & $* S$ \\
\hline
\end{tabular}

“t” df (62) = 2.00; $\mathrm{p}<0.05 ;{ }^{*}$ Significant $\left({ }^{*} \mathrm{~S}\right) /$ Not significant (NS). 
nursing student have significant lower mean score than that of general college students. In support of this result, the conclusion from study by $A b d r b o A^{3}$ on 'Self-Assessment of Leadership Behaviours' among baccalaureate nursing students, may be added as an essential recommendation of constant provision of leadership education in nursing curriculum along with extra-curricular training.

The present study also aimed at identifying correlation between assertiveness, self-esteem and leadership potentiality. The study results reveal that there is significant correlation between self-esteem and leadership potentiality. But the study finds out that there is no significant correlation between assertiveness and self-esteem which is inconsistent with the study conducted by Maheshwari SK, Gill KK ${ }^{11}$ in an explanatory, co-relational, cross-sectional survey upon 220 nurses in Punjab, India in 2015, identified moderate positive correlation between assertiveness and self-esteem among nurses.

Study was limited to selected setting and non-purposive total enumeration sampling technique limited number of samples.

Following recommendations may be drawn that a similar study can be replicated on large sample for generalization, or different settings can be selected or similar study can be conducted among different population (e.g. government and private nursing colleges). An exploratory study can be conducted to identify factors associated with low level of assertiveness, self-esteem and leadership potentiality among nursing students. Experimental study can be conducted to assess effectiveness of assertiveness training, specific leadership skill training, etc.

\section{Conclusion}

The study shows that assertiveness, self-esteem and leadership potentiality among general college students are higher than among nursing college students. It is necessary to explore reasons for low assertiveness, self - esteem and leadership potentiality among nursing students and find ways and means to inculcate assertiveness, self-esteem and leadership potentiality in nursing students so that they can meaningfully execute their professional responsibilities, thereby rendering quality nursing care leading to better health of individuals.

\section{Conflicts of Interest: None}

\section{References}

1. Hemavathy $\mathrm{V}$, Christy CM. A descriptive study to assess the assertiveness skills among post graduate nursing students. International Journal of Humanities, Arts, Medicine and Sciences 2016; 4(1): 29-32.

2. Townsend MC. Psychiatric mental health nursing: concepts of care in evidence-based practice. $8^{\text {th }}$ ed.
Jaypee Brothers Medical Publishers (P) Ltd., New Delhi. 2015; 15: 248, 257.

3. Abdrbo AA. Self-assessment of leadership behaviors among baccalaureate nursing students with different clinical training experience and nurses. International Proceedings of Economics Development and Research 2012; 37: 106-109.

4. Walczak MB, Absolon PL. Essentials for effective communication in oncology nursing: assertiveness, conflict management, delegation, and motivation. Journal for Nurses in Staff Development 2001; 17(3): 159-162.

5. Larijani TT, Aghajani M, Zamani N et al. Assertiveness and factors affecting it among nursing students of Tehran university of medical sciences. International Journal of New technology and Research 2017; 3(5): 34-38.

6. Duruk N, Kurban NK, Kurban O. An example of nursing students' self-esteem: does university education make a difference? International Journal of Caring Sciences 2017: 10(3): 1577-1579.

7. Dharsini DDP, Jebaseelan US. Study on self-esteem among the college students in Tiruchirapalli district. International Institute for Science, Technology and Education 2017; 7(17).

8. Bhowmik S. Relationship of assertive behaviour, selfesteem and academic performance among adolescents. MSc. Nursing [Dissertation]. Guwahati University, Guwahati. 2018.

9. BNS111. Nursing Education and Research. Indira Gandhi National Open University School of Health Sciences. Aravali Printers and Publishers (P) Ltd., Delhi. 2005; 16, 17.

10. Okuyama A, Wagner C, Bijnen B. How we can enhance nurses' assertiveness: a literature review. The Journal of Nursing Care 2014; 3(5): 1-9.

11. Maheshwari SK, Gill KK. Relationship of assertiveness and self-esteem among nurses. International Journal of Health Sciences and Research 2015; 5(6): 440-1. 